\title{
Asking the Right Questions About Leadership: Discussion and Conclusions
}

\section{Citation}

Hackman, J. Richard, and Ruth Wageman. 2007. Asking the right questions about leadership: Discussion and conclusions. American Psychologist 62, no. 1: 43-47.

\section{Published Version}

http://dx.doi.org/10.1037/0003-066X.62.1.43

\section{Permanent link}

http://nrs.harvard.edu/urn-3:HUL.InstRepos:3228648

\section{Terms of Use}

This article was downloaded from Harvard University's DASH repository, and is made available under the terms and conditions applicable to Other Posted Material, as set forth at http:// nrs.harvard.edu/urn-3:HUL.InstRepos:dash.current.terms-of-use\#LAA

\section{Share Your Story}

The Harvard community has made this article openly available.

Please share how this access benefits you. Submit a story.

\section{Accessibility}




\title{
Asking the Right Questions About Leadership
}

\author{
Discussion and Conclusions
}

\author{
J. Richard Hackman Harvard University \\ Ruth Wageman Dartmouth College
}

Five questions prompted by the articles in the American Psychologist special issue on leadership (January 2007, Vol. 62, No. 1) suggest some new directions for leadership research: (1) Not do leaders make a difference, but under what conditions does leadership matter? (2) Not what are the traits of leaders, but how do leaders' personal attributes interact with situational properties to shape outcomes? (3) Not do there exist common dimensions on which all leaders can be arrayed, but are good and poor leadership qualitatively different phenomena? (4) Not how do leaders and followers differ, but how can leadership models be reformulated so they treat all system members as both leaders and followers? (5) Not what should be taught in leadership courses, but how can leaders be helped to learn?

Keywords: leadership theory, leaders, followers, learning, traits

5 f or all of the research that has been conducted on the topic of leadership, the field remains curiously unformed. Leadership scholars, including those who have written for this special issue, agree that leadership is extraordinarily important both as a social phenomenon and as a subject for scholarly research and theory. Yet, as both Bennis (2007, this issue) and Vroom and Jago (2007, this issue) have pointed out, there are no generally accepted definitions of what leadership is, no dominant paradigms for studying it, and little agreement about the best strategies for developing and exercising it.

Among the many possible reasons for this gloomy state of affairs is that leadership scholars over the years may have been asking questions that have no general answers, thereby adding complexity but not clarity to our understanding. The articles that comprise this special issue summarize a great deal of informative research about leadership, to be sure. But perhaps their greatest contribution is that they raise a number of questions the answers to which will help us develop knowledge about leadership that is interesting, useful, and cumulative. In answer to Bennis's (2007, this issue) plea that scholars use their creativity to identify and reframe the most important questions about leadership, we pose in this concluding essay five questions that were prompted by the articles in this issue. We hope that these questions may be somewhat more informative, or at least more tractable, than some that have historically been prominent in leadership research.
Question 1: Not do leaders make a difference, but under what conditions does leadership matter? As the authors of these articles have noted, the long-standing debate between leader-centric and structural or situational explanations of collective performance has never been resolved, and probably cannot be. The reason is that the debate is about the wrong question. The right question is to distinguish conceptually and empirically those circumstances in which leaders' actions are highly consequential for system performance from those in which leaders' behaviors and decisions make essentially no difference (Avolio, 2007, this issue; Chan \& Brief, 2005; Hackman \& Wageman, 2005; Vroom \& Jago, 2007, this issue; Wasserman, Nohria, \& Anand, 2001).

This question invites observers of leadership to swim upstream against strong attributional currents. Lay observers, as well as not a few leadership scholars, tend to view leaders as a dominant influence on system performance (see Bennis, 2007, this issue). But are leaders really a main, or the main, influence on what transpires in social systems? Or does our tendency to view them that way merely reflect what Meindl (1990) called the "romance" of leadership? Consider, for example, how we explain an athletic team that has winning season after winning season. "That John Wooden at UCLA!" we exclaim. "What a basketball coach he was!" Or reflect on a team that has had a few losing seasons: It is the coach who is fired. We refer to this tendency to identify the leader as the main cause of collective performance as the leader attribution error. The leader attribution error is understandable (both because of the high visibility of leaders and the relative invisibility to observers of structural or contextual factors that may be powerfully shaping outcomes), it is pervasive (it occurs for both favorable and unfavorable outcomes), and it is powerful (system members as well as observers are vulnerable to it) (Hackman, 2002, chap. 6; Hackman \& Wageman, 2005).

J. Richard Hackman, Department of Psychology, Harvard University; Ruth Wageman, Tuck School of Business, Dartmouth College.

Preparation of this essay was supported in part by the Center for Public Leadership, John F. Kennedy School of Government, Harvard University. Some material presented here is based on previous work by the authors (Hackman, 2002; Hackman \& Wageman, 2005).

Correspondence concerning this article should be addressed to J. Richard Hackman, Department of Psychology, 33 Kirkland Street, Harvard University, Cambridge, MA 02138. E-mail: hackman@fas.harvard.edu 


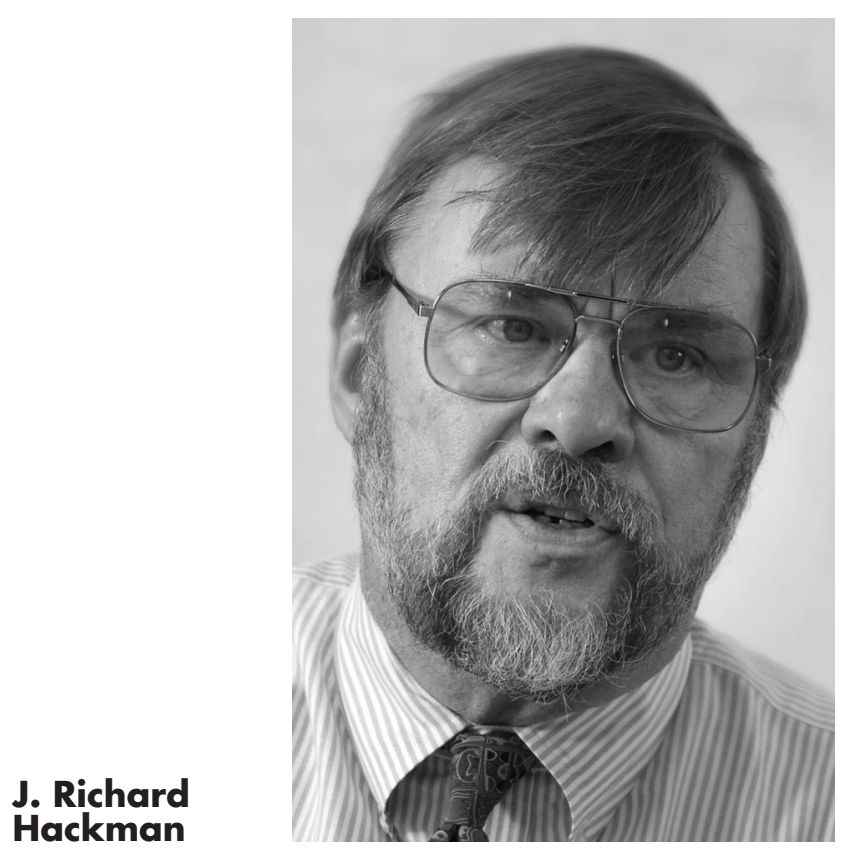

The interactionist position is entirely sensible and acknowledges what has been found in decades of research on leadership. Still, it is a mark of the pervasiveness and power of dispositional thinking that the authors, without exception, offered readers their own lists of the leader traits that they believe to be most important. Moreover, with the exception of Vroom and Jago (2007, this issue), they offered relatively few suggestions about what the key leadership-relevant attributes of situations might be.

Although it is indisputable that any robust model of leadership must address the interaction between personal and situational attributes, how should that interaction be framed? The generally accepted strategy is to deploy a contingency model (for a review of such models, see Avolio, 2007, this issue). That is, if the direct relationship between some leader attribute $X$ and some outcome measure $Y$ is insubstantial, or if its size or direction changes in different settings, then a situational variable $Z$ is posited as a moderator of the $X-Y$ relationship. Aside from the statistical difficulties of documenting moderating effects (Lubinski \& Humphreys, 1990), contingency models necessarily become quite complex as research identifies increasing numbers of potential moderators. In that inevitability lies the rub: The more complete and complex a contingency model of leadership, the less conceptually elegant and practically useful it is. Moreover, if the contingency involves the actual behavior of a leader, as is the case for many of the models discussed in these articles, a level of online processing by the leader is required that can exceed human cognitive capabilities (Gigerenzer, 1999; Simon, 1990).

The systems theorists' notion of equifinality (Katz \& Kahn, 1978, p. 30) offers one possible strategy for circumventing the inherent difficulties of contingency models. Equifinality posits that there are many different ways that an open system (such as a person, a group, or an organization) can behave and still achieve the same outcome. When applied to leadership, equifinality implies that different leaders can behave in their own quite idiosyncratic ways and still get key leadership tasks accomplished. Rather than try to tailor their behaviors or styles to some set of contingent prescriptions, then, excellent leaders know how they prefer to operate, what they are able to do easily and well, and what they can accomplish only with difficulty if at all. They may never have heard of the principle of equifinality, but they behave in accord with it. This approach, perhaps, could extract psychologists from overreliance on either fixed traits or complex contingencies in leadership studies-especially if scholars take seriously the proposal by Avolio (2007, this issue) that robust leadership theories must acknowledge the reality that leader behavior is shaped by multiple factors operating at different levels of analysis. Although scholars have not yet carried out the conceptual or empirical work that would be required to explore the application of the principle of equifinality to leader behavior, the effort just might generate nontrivial advances in how we construe, study, and practice leadership. 


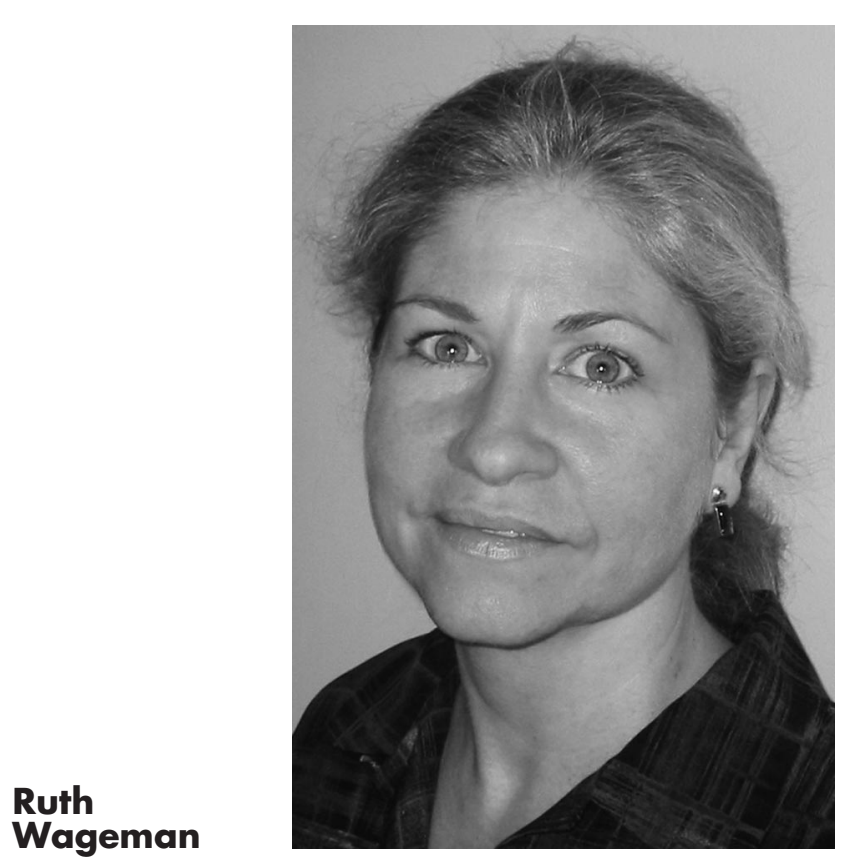

Question 3: Not do there exist common dimensions on which all leaders can be arrayed, but are good and poor leadership qualitatively different phenomena? As noted by the authors of the articles in this issue, leadership scholars have devoted considerable effort over the decades to identifying dimensions that reliably summarize and describe leader behavior and style. The most prominent of these, of course, are "Initiation of Structure" and "Consideration," which emerged from the Ohio State Studies (Fleishman, 1973). Any leader can be assigned a score in the two-dimensional space defined by these dimensions, on the basis of self-reports and/or the ratings of others. A great deal of research has been conducted using leaders' standing on these dimensions to assess both (a) the impact of leader behavior on subordinates and on unit performance and, more recently, (b) the impact of subordinate behavior and contextual conditions on leader behavior itself. The aspiration has been to identify those leadership behaviors and styles that are most appropriate and effective under various conditions.

The scores of leaders on such dimensions can range from "low" to "high" (in practice, of course, actual numerical scores are computed). But what if good and poor leadership actually were qualitatively different phenomena, if there were no single dimension on which both good and poor leaders could be meaningfully arrayed? That possibility is not as unlikely as it may seem. In fact, there are many social and psychological phenomena for which two different systems are required to distinguish one extreme from the other. Positive and negative affect, for example, appear to involve different neural systems. Rewards have qualitatively different effects on organisms than do punishments. The prospect of losing resources is qualitatively different from the prospect of a gain. And those who study human competencies compare excellent performers with average performers rather than with poor performers precisely because demonstrating competence invariably involves different processes than does behaving incompetently.

The same asymmetry may operate for leadership. Research by Ginnett (1993) on the leadership of airline captains, for example, showed that leaders who had been identified by their peers as excellent crew leaders used their authority to accomplish three generic functions (bounding the crew as a performing unit, helping the crew come to terms with its task, and establishing basic norms of conduct for the team). Leaders who had been identified as poor crew leaders, by contrast, did not merely fail to accomplish these three leadership functions; instead, they all exhibited some kind of difficulty with control issues (for example, being overcontrolling, or undercontrolling, or vacillating between the two). Poor leaders were not individuals with low scores on the same dimensions on which good leaders excelled; instead, they exhibited entirely different patterns of behavior.

As Bennis (2007, this issue) noted, there is increasing interest these days in the dynamics of "bad" leadership. What has been learned thus far is consistent with the possibility that good and bad leadership may be qualitatively different phenomena (Kellerman, 2004). That possibility is further reinforced by Sternberg's (2007, this issue) proposal that wisdom, defined as the leader's use of his or her intelligence, creativity, and knowledge to promote the common good, is a key ingredient of effective leadership. Unsuccessful leaders, Sternberg suggested, do not merely lack wisdom; they also fall victim to a series of cognitive fallacies that effective leaders do not. Further research on the special and separate dynamics that characterize good and poor leadership, each as contrasted with "average" leadership or with no leadership at all, may well bring to the surface insights about leadership that otherwise would remain unnoticed.

Question 4: Not how do leaders and followers differ, but how can leadership models be reframed so they treat all system members as both leaders and followers? The authors of several of the articles in this issue made the point that leaders must have followers. Although certainly correct, that assertion also implicitly reinforces the traditional view, discussed by Avolio (2007, this issue), that leaders act and followers mainly react. The opposite is true as well, however: Leaders also are followers, and followers also exhibit leadership.

There are few, if any, organizational or political leaders who have unchecked authority. Each boss also is a subordinate- even chief executives who lead entire organizations invariably report to some higher-standing person or group. This reality means that people who hold formal leadership positions must continuously chart a course between what essentially is a covert coup (acting as if one's own leader need not know what one is doing) and abdication (mindlessly passing on to one's subordinates whatever is received from above). It can take a good measure of skill and personal maturity to balance between one's simulta- 
neous roles as leader and as follower, and the dynamics of managing that balance may deserve more research attention than they have thus far received.

Moreover, as Bennis (2007, this issue) noted, every follower is, at least potentially, also a leader. This fact was empirically illustrated in our recent study of analytic teams in the U.S. intelligence community (Hackman \& O'Connor, 2004). Data about the time allocation of the teams' leaders showed that they spent most of their time structuring the work, running external interference, and coaching individual employees. Of all the leader activities we assessed, working directly with their teams received the least attention. That fact opened up many opportunities for peer leadership among rank-and-file team members. And it turned out that the amount of peer coaching members provided one another correlated more strongly with our criterion of team effectiveness $(r=.82)$ than did any other variable we measured. Clearly, most of the hands-on leadership these teams received was provided by members themselves-and to good effect.

To the extent that leadership and followership are inextricably bound up with one another, the distinction between leaders and followers becomes blurred and the whole idea of "shared leadership" takes on a new meaning. In this view, shared leadership is far more than just a partnership or the use of a "participative" style. Instead, it raises the possibility, first suggested decades ago by McGrath (1962), that anyone who fulfills critical system functions, or who arranges for them to be fulfilled, is exhibiting leadership. The functional approach to leadership is the one that we find most intellectually agreeable, and we have written at some length about its implications for the leading of task-performing teams (Hackman, 2002; Hackman \& Wageman, 2005; Wageman \& Mannix, 1998). It remains to be seen whether the functional approach also is useful in understanding the leadership of larger and more complex entities such as whole organizations or nations.

As the authors of several articles in this issue have noted, psychologists devoted considerable attention in the early decades of leadership research to identifying the attributes that distinguish leaders from nonleaders (i.e., followers). Indeed, Zaccaro (2007, this issue) argued that the same traits that differentiate leaders and followers also contribute to a person's effectiveness in enacting the leadership role. We concur that much is known about who is likely to become a leader, but we suggest that it was not psychologists who were mainly responsible for generating this knowledge - it was, instead, our friends from one level up, the sociologists. If one wants to know who is likely to occupy a position of formal leadership, there is no better place to look than the opportunity structure of society. Or, to put it more colloquially: If you want to be king, your best bet is to be the son of a king or queen.

Although people who occupy leadership roles certainly have more latitude to lead than do followers, one does not have to be in a leadership position to be in a position to provide leadership. Indeed, among the most interesting, and occasionally inspiring, varieties of leadership we have observed is that provided by followers, es- pecially followers who are unlikely ever to be selected for formal leadership positions.

Question 5: Not what should be taught in leadership courses, but how can leaders be helped to learn? The articles in this section document that all leaders have mental models that guide their actions. Because these models are abstracted gradually over time from observations, experience, and trial and error, they risk overfocusing on especially salient features of the leadership situation. Thus, the behavior of another leader one has observed, or especially vivid personal episodes, or the dispositions of a particularly difficult boss or subordinate, may become more central in a leader's mental model than is actually warranted.

Ideally, leaders would be motivated to behave in ways that foster their own continuous learning from their experiences. Sternberg (2007, this issue) proposed that such learning is far more readily accomplished than would be suggested by leadership models that emphasize the importance of fixed traits or capabilities. Yet, as Sternberg also noted, continuous learning almost always requires that leaders overcome inherently self-limiting aspects of their existing mental models. Because such models become so well learned that they are virtually automatic, leaders may not even be aware of the degree to which their models are shaping their leadership behaviors. For this reason, Vroom and Jago (2007, this issue) suggested that leadership training must both bring to the surface trainees' own preferred leadership strategies and then explore the conditions under which those strategies are and are not appropriate.

Any personal leadership model is certain to be flawed or incomplete in some significant way and therefore certain to spawn occasional errors or failures. Since implicit models are not recognized as having contributed to the failure, however, a leader's response is more likely to be defensive (e.g., blaming chance or others for what happened) than learning oriented (e.g., inspecting the assumptions that guided the behavior that generated the failure).

Avolio (2007, this issue) suggested that new research is needed to fully understand how leaders learn from their experiences, especially when they are coping with crises. We go further and suggest that error and failure provide far more opportunities for learning than do success and achievement, precisely because failures generate data that can be mined for insight into how one's assumptions and models of action might be improved. Overcoming the impulse to reason defensively, however, can be a significant personal challenge. It necessarily involves asking anxiety-arousing questions (e.g., about the validity of deeply held assumptions or about personal flaws in diagnosis or execution), gathering data that can help answer those questions, and then altering one's mental models and behavioral routines. As Argyris (1991) has shown, such activities are neither natural nor comfortable. Moreover, they are likely to be especially challenging for senior leaders, who precisely because they have track records of leadership success, may have limited experience in learning how to learn from error and failure. 
Leading well, therefore, may require a considerable degree of emotional maturity in dealing with one's own and others' anxieties. Emotionally mature leaders are willing and able to move toward anxiety-arousing states of affairs in the interest of learning about them, rather than moving away from them to get anxieties reduced as quickly as possible. Moreover, such leaders are able to inhibit impulses to act (e.g., to correct an emerging problem or to exploit a suddenly appearing opportunity) until more data have appeared or until system members become open to the contemplated intervention. Sometimes it is even necessary for leaders to engage in actions that temporarily raise anxieties, including their own, to lay the groundwork for subsequent interventions that seek to foster learning or change.

Unlike the cognitive and behavioral leadership challenges addressed in the articles in this issue, emotional maturity may be better viewed as a long-term developmental task than as something that can be systematically taught. Emotional learning cannot take place in the abstract or by analyzing a case of someone else's failure. Instead, it involves working on real problems in safe environments with the explicit support of others. Only to the extent that leader development programs take on the considerable challenge of providing such settings are they likely to be helpful to leaders both in developing their own learning habits and in providing models for those they lead to pursue their own continuous learning.

\section{REFERENCES}

Argyris, C. (1991, May-June). Teaching smart people how to learn. Harvard Business Review, 5-15.

Avolio, B. J. (2007). Promoting more integrative strategies for leadership theory building. American Psychologist, 62, 25-33.

Bennis, W. (2007). The challenges of leadership in the modern world: Introduction to the special issue. American Psychologist, 62, 2-5.

Chan, S., \& Brief, A. R. (2005). When leadership matters and when it does not: A commentary. In D. M. Messick \& R. M. Kramer (Eds.), The psychology of leadership (pp. 321-332). Mahwah, NJ: Erlbaum.

Fleishman, E. A. (1973). Twenty years of consideration and structure. In
E. A. Fleishman \& J. G. Hunt (Eds.), Current developments in the study of leadership (pp. 1-37). Carbondale: Southern Illinois University Press.

Gigerenzer, G. (1999). Fast and frugal heuristics: The adaptive toolbox. In G. Gigerenzer \& P. M. Todd (Eds.), Simple heuristics that make us smart (pp. 3-34). New York: Oxford University Press.

Ginnett, R. C. (1993). Crews as groups: Their formation and their leadership. In E. L. Wiener, B. G. Kanki, \& R. L. Helmreich (Eds.), Cockpit resource management (pp. 71-98). Orlando, FL: Academic Press.

Hackman, J. R. (2002). Leading teams: Setting the stage for great performances. Boston: Harvard Business School Press.

Hackman, J. R., \& O'Connor, M. (2004). What makes for a great analytic team? Individual vs. team approaches to intelligence analysis. Washington, DC: Intelligence Science Board, Office of the Director of Central Intelligence.

Hackman, J. R., \& Wageman, R. (2005). When and how team leaders matter. Research in Organizational Behavior, 26, 37-74.

Katz, D., \& Kahn, R. L. (1978). The social psychology of organizations (2nd ed.). New York: Wiley.

Kellerman, B. (2004). Bad leadership: What it is, how it happens, why it matters. Boston: Harvard Business School Press.

Lubinski, D., \& Humphreys, L. G. (1990). Assessing spurious "moderator effects": Illustrated substantively with the hypothesized ("synergistic") relation between spatial and mathematical ability. Psychological Bulletin, 107, 385-393.

McGrath, J. E. (1962). Leadership behavior: Some requirements for leadership training. Washington, DC: U.S. Civil Service Commission.

Meindl, J. R. (1990). On leadership: An alternative to the conventional wisdom. Research in Organizational Behavior, 12, 159-203.

Simon, H. A. (1990). Invariants of human behavior. Annual Review of Psychology, 41, 1-19.

Sternberg, R. J. (2007). A systems model of leadership: WICS. American Psychologist, 62, 34-42.

Vroom, V. H., \& Jago, A. G. (2007). The role of the situation in leadership. American Psychologist, 62, 17-24.

Wageman, R., \& Mannix, E. A. (1998). Uses and misuses of power in task-performing teams. In R. Kramer \& M. Neale (Eds.), Power, politics, and conflict in organizations (pp. 261-285). Greenwich, CT: JAI Press.

Wasserman, N., Nohria, N., \& Anand, B. N. (2001). When does leadership matter? The contingent opportunities view of CEO leadership (Strategy Unit Working Paper No. 02-04; Harvard Business School Working Paper No. 01-0630, available from http://ssrn.com/ abstract $=278652$ ). Manuscript submitted for publication.

Zaccaro, S. J. (2007). Trait-based perspectives of leadership. American Psychologist, 62, 6-16. 